\title{
Perspectives on assessing the emotional behaviour of animals with behaviour problems
}

Daniel S Millsmills

Animal Behaviour, Cognition and Welfare Group, School of Life Sciences, University of Lincoln, Lincoln LN6 7DL, UK

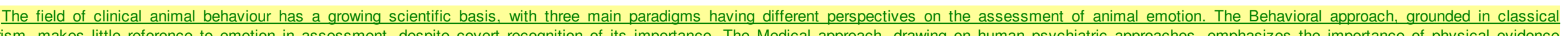

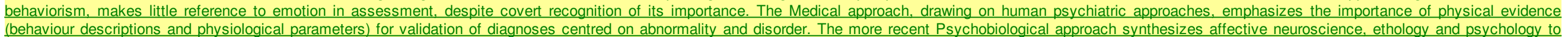

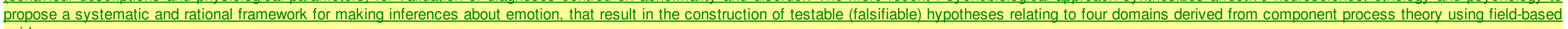
evidence.

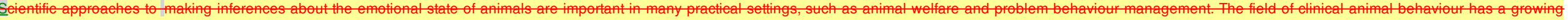

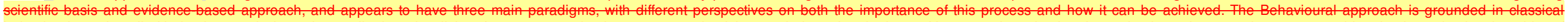

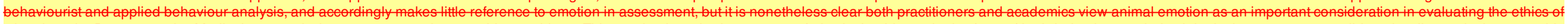

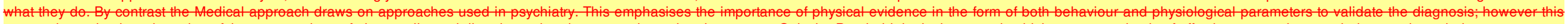

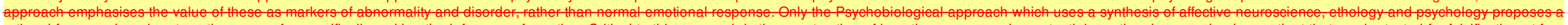

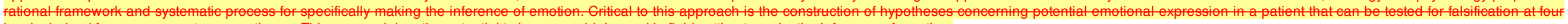
tevels derived from component process theory. This approach has the potential to be moro widely used in field selting to make the inference of omotion,

Current Opinion in Behavioral Sciences 2017, 16:xx-yy

This review comes from a themed issue on Comparative cognition

Edited by Ben Hayden-and Jessica F Cantlon

http://dx.doi.org/10.1016/j.cobeha.2017.04.002

2352-1546/@ 2017 Elsevier Ltd. All rights reserved.

\section{Introduction}

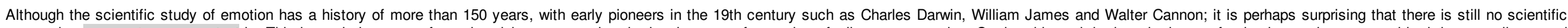

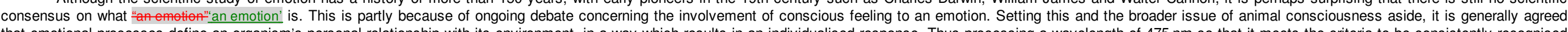

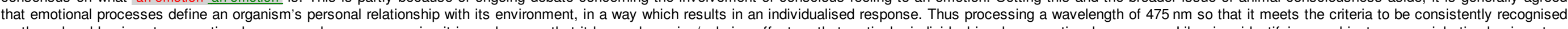

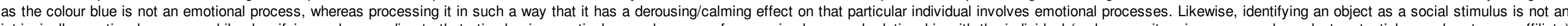

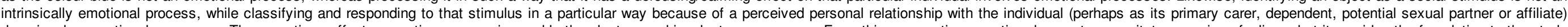

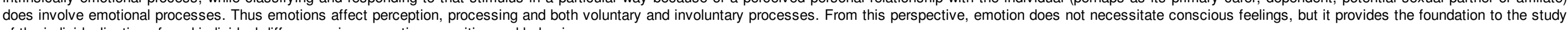
of the individualisation of, and individual differences in, perception, cognition and behaviour.

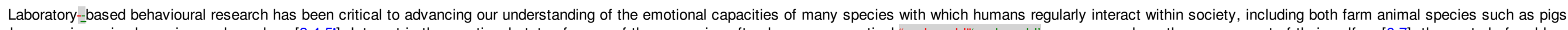

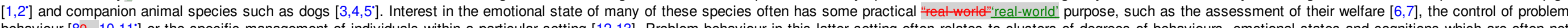

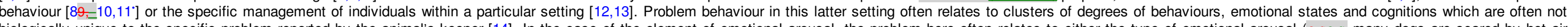

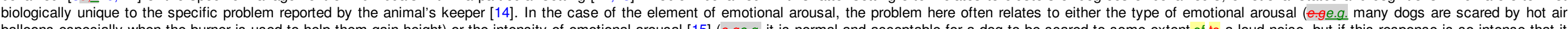

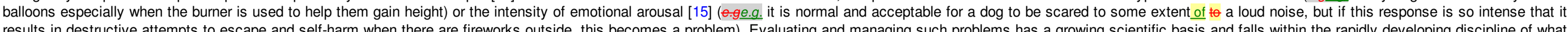

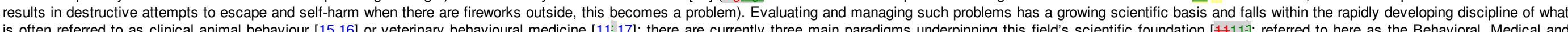

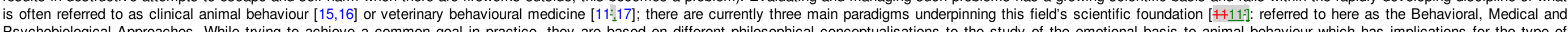

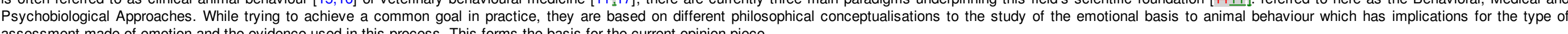
assessment made of emotion and the evidence used in this process. This forms the basis for the current opinion piece.

\section{Behavioral Approach}

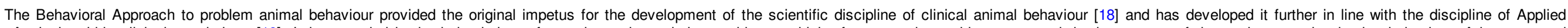

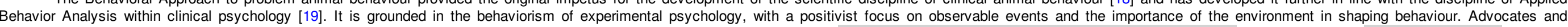

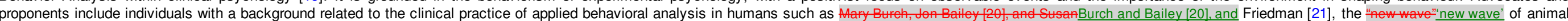

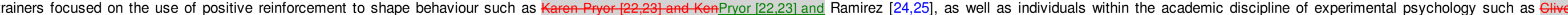

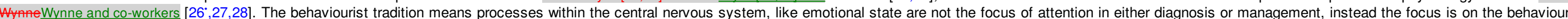

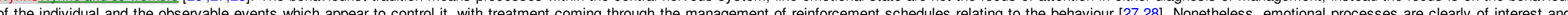




\section{elsevier_COBEHA_361}

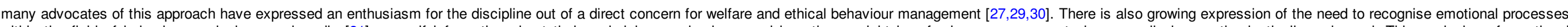

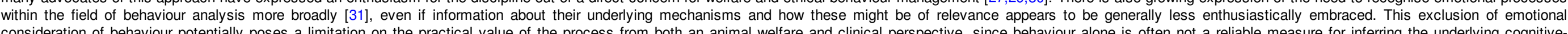

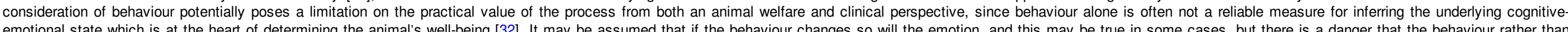

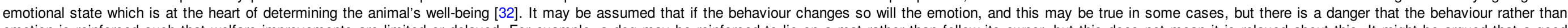

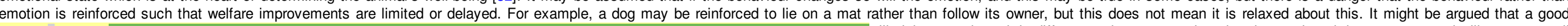

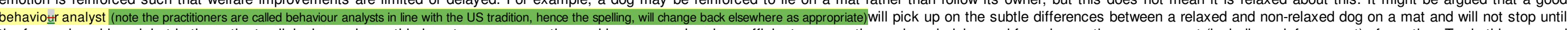

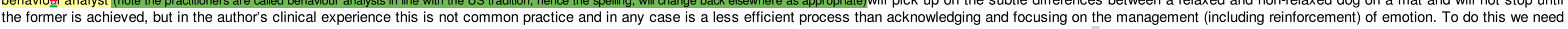
a systematic scientific process to infer emotion which goes beyond an indirect inference from just the overt behaviour of the animal, which is the process used by behaviourists.

\section{Medical Approach}

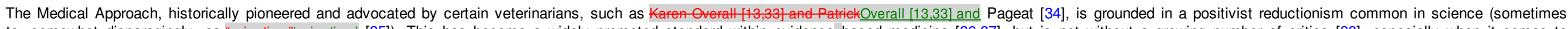

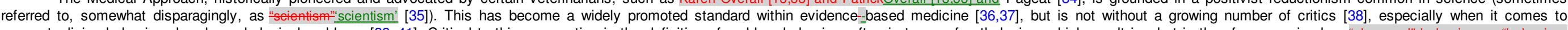

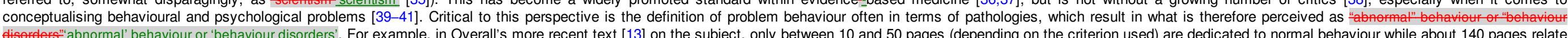

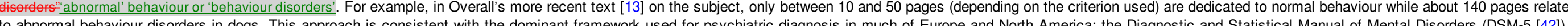

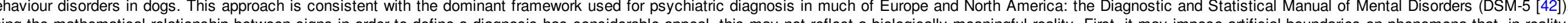

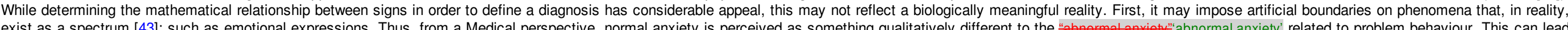

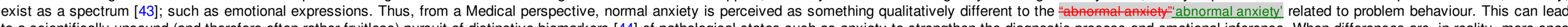

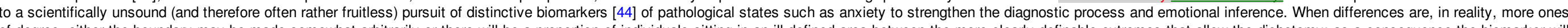

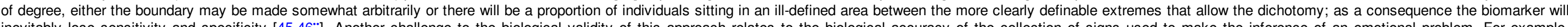

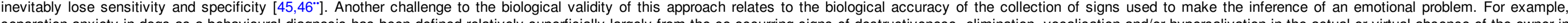

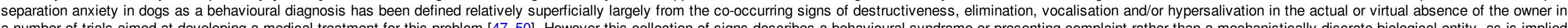

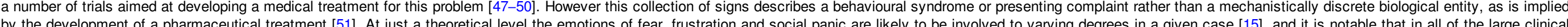

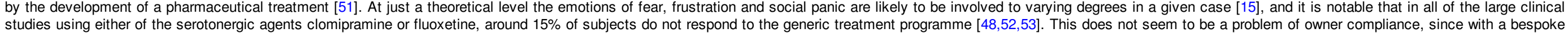

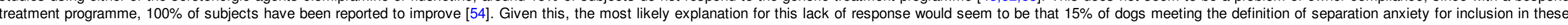

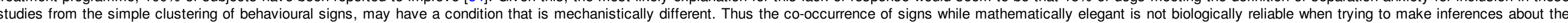

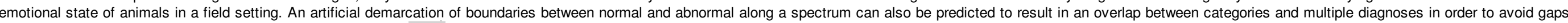

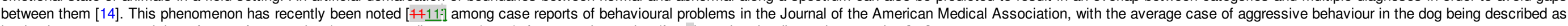
having between two and three forms of aggression (average 2.4 diagnoses/case), for example, anxiety/fear-based and redirected aggression [55].

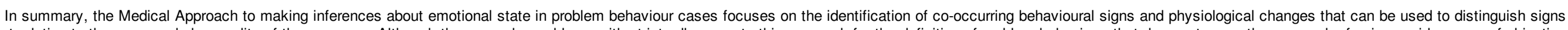

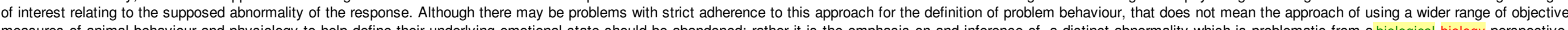

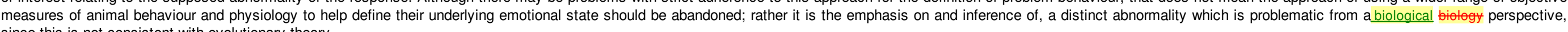
since this is not consistent with evolutionary theory.

\section{Psychobiological Approach}

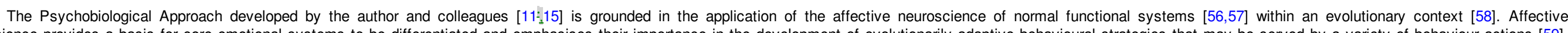

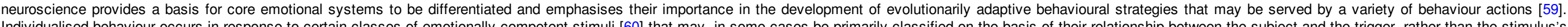

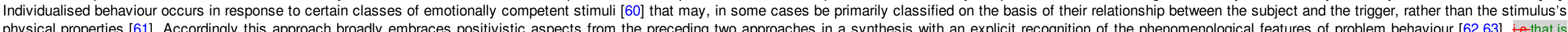

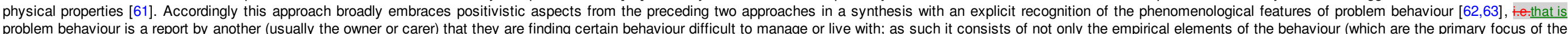

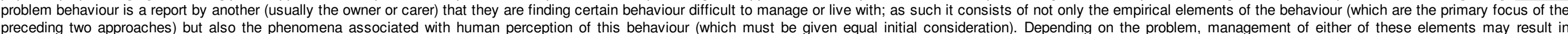

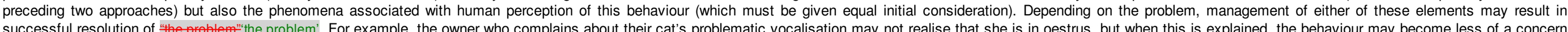

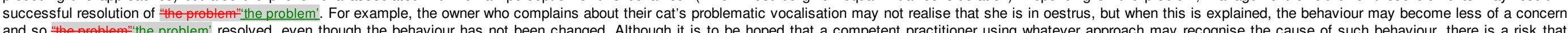

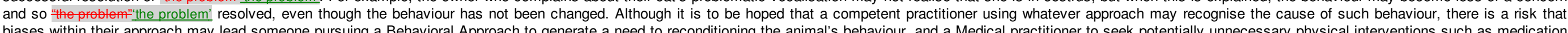

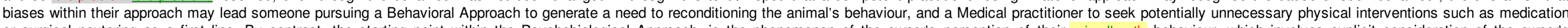

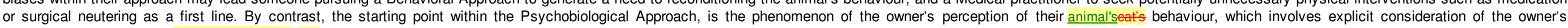

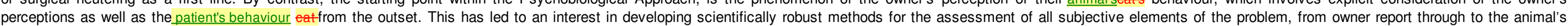

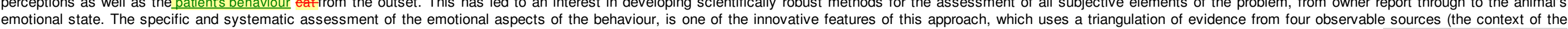

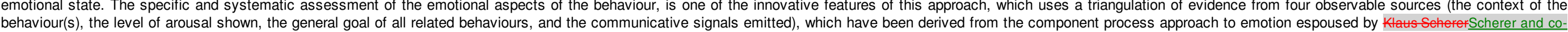

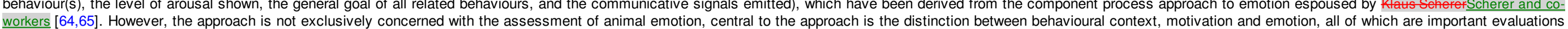
but which historically have been confused [66]. In the author's opinion this Psychobiological Approach provides a rigorous scientific framework for the inference of emotion by achieving the following:

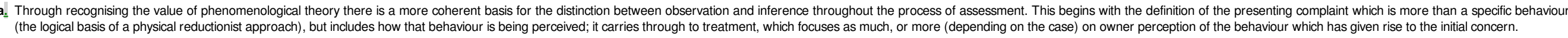

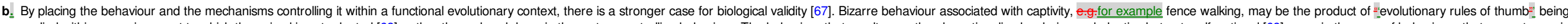

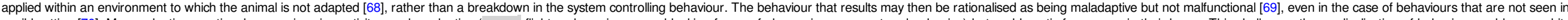

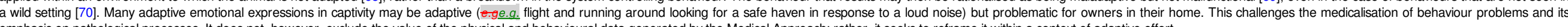
emphasis on pathological processes. It does not, however, exclude the value of the physical and behavioural data generated by the Medical Approach; rather, it seeks to reframe it within a context of adaptive effort.

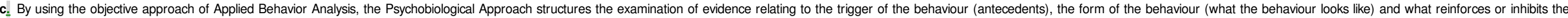




\section{elsevier_COBEHA_361}

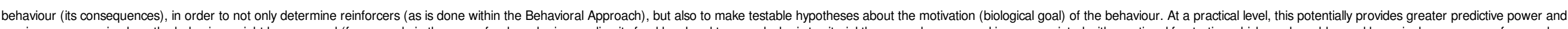

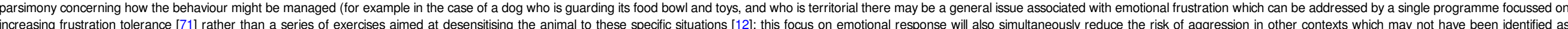

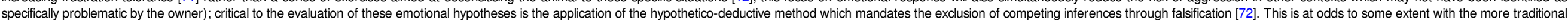
verification of diagnoses through the accumulation of positive evidence (such as physiological markers of the problem) that is common within the medical approach to diagnosis.

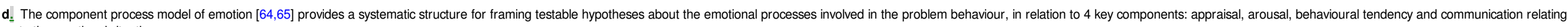
to the emotional situation.

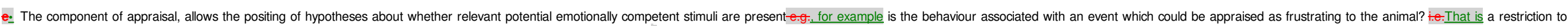
autonomous control (a fuller list of categories used in a clinical behaviour setting have been described elsewhere $\left[11_{1}^{*} 15,73^{*}\right]$ and have been derived from a review of the common emotional behaviour networks in the brain of mammals);

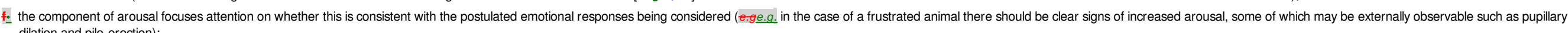
dilation and pilo-erection):

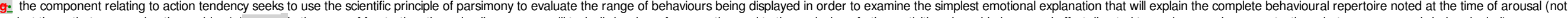

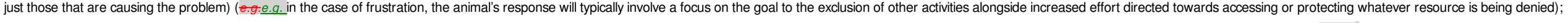

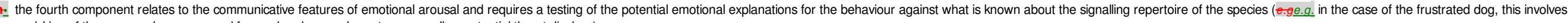
a pricking of the ears, and more general forward and upwards posture, as well as potential threat displays).

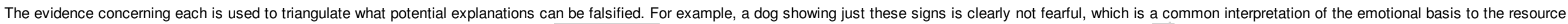
guarding dog, where the frustration at the potential loss of a resource is often referred to an "anxiety"'anxiety" (implying engagement of the emotional fear system) about potential loss [ $z 2:]$.

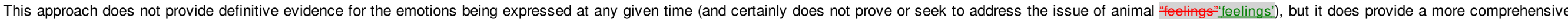

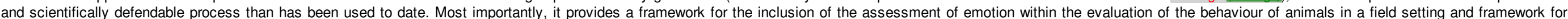

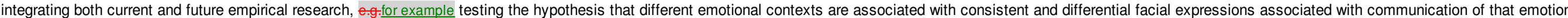

\section{Conclusion}

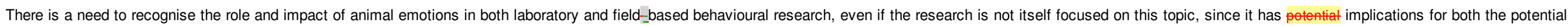

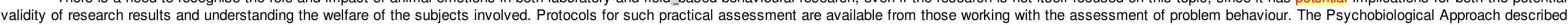

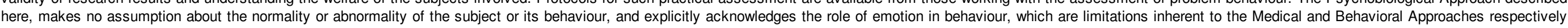

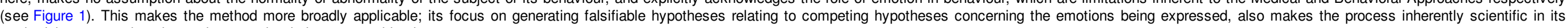
methodology, even though emotions are, by their nature, subjective states.

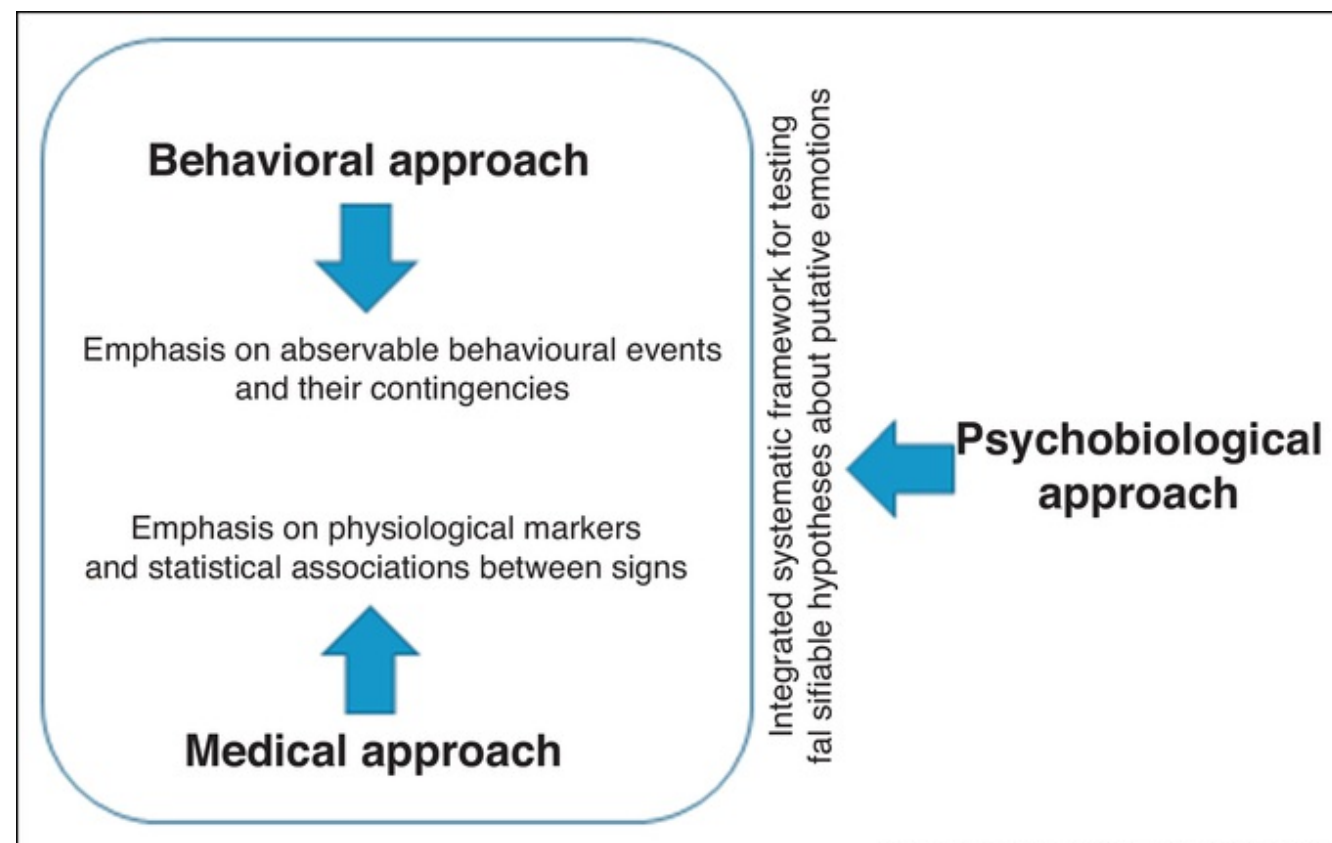

Current Opinion in Behavioral Sciences

Fiaure 1 Main contributions of different paradigms (shown in bold) within clinical animal behaviour to the assessment of animal emotion in the field.




\section{elsevier_COBEHA_361}

\section{References and recommended reading}

Papers of particular interest, published within the period of review, have been highlighted as:

- of special interest

.. of outstanding interest

\section{References}

1

. E.T. Gieling, R.E. Nordquist and F.J. van der Staay, Assessing learning and memory in pigs, Animalcognition.142. Cogn. 14, 2011, 151-173.

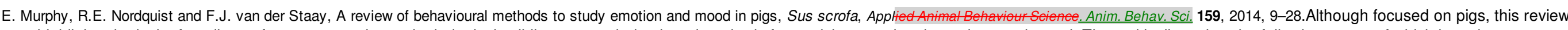

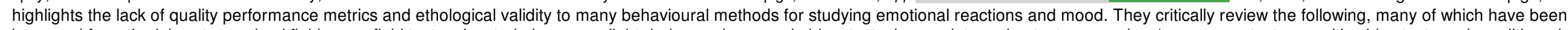

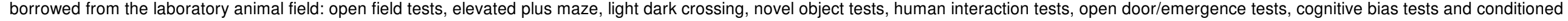
discrimination tests, as well as more general assessments of emotional behaviour including play, vocalisation, anticipatory behaviour and qualitative behavioural assessment methods.

3

. N. Albuquerque, K. Guo, A. Wilkinson, C. Savalli, E. Otta and D. Mills, Dogs recognize dog and human emotions, Biologyletters127. Lett. 12, 2016, 20150883.

4

. M.K. Bensky, S.D. Gosling and D.L. Sinn, The world from a dog's point of view: a review and synthesis of dog cognition research, Advaneesin the Study of Animal Behavior. Study Anim. Behav. 45, 2013, 209-406.

$5 \cdot$

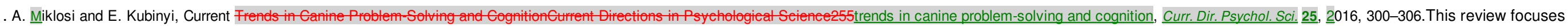

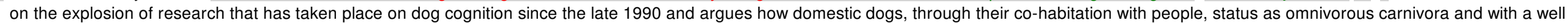
sequences genome are unique models for comparative cognition. The highlight the importance of studying developmental processes and our dependence on the dated, but classic work of the 1960.

6

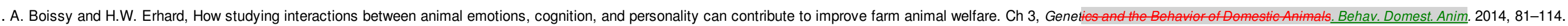

7

M. Walker, M. Diez-Leon and G. Mason, Animal welfare science: Arecent publication trends and future research priorities, Intrational Journal of Comparative Psyehology271. J. Comp. Psychol. 27, 2014, 80-100.

8

. M. Dawkins, Animal suffering: the seience of animal wSuffering: The Science of Animal Welfare, 2012, Springer Science \& Business Media.

9

T. Grandin, Improving animal welfare: a praetieal aAnimal Welfare: A Practical Approach, 2015, CABI.

10

. F. Ohl and F.J. Van der Staay, Animal welfare: Aat the interface between science and society, The Veterinary dournal1921 Vet. J. 192, $2012,13-19$.

11.

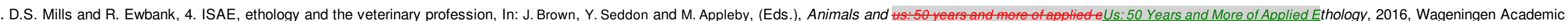

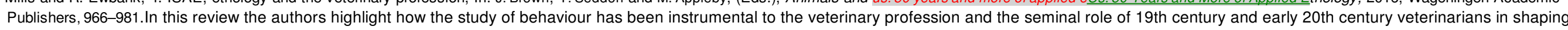

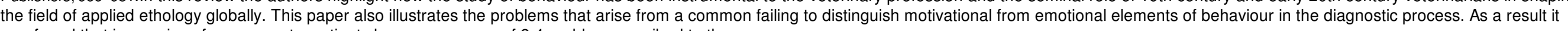
was found that in a series of case reports, patients have an average of 2.4 problems ascribed to them.

12

. G.M. Landsberg, W.L. Hunthausen and L.J. Ackerman, Behavior Problems of the Dog and Cat, 2012, Elsevier Health Sciences.

13

.K. Overall, Manual of elinieal behavioral medieine for dogs and e Clinical Behavioral Medicine for Dogs and Cats, 2013, Elsevier Health Sciences.

14

. G. Sheppard and D.S. Mills, Construct models in veterinary behavioural medicine: lessons from the human experience, Veterinary researeh communications273. Res. Commun. 27, 2003, 175-191. 


\section{elsevier_COBEHA_361}

. D.S. Mills, M.B. Dube and H. Zulch, Stress and pheromonatherapy in small animat elinieal bPheromonatherapy in Small Animal Clinical Behaviour, 2012, John Wiley \& Sons.

16

. B. Hothersall and R. Casey, Undesired behaviour in horses: Aa review of their development, prevention, management and association with welfare, Equine Veterinary Education249. Educ. 24, 2012, 479-485.

17

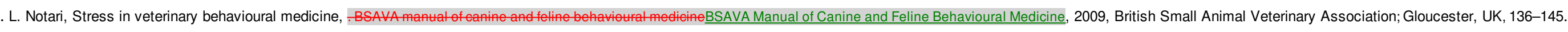

18

. D.S. Tuber, D. Hothersall and V.L. Voith, Animal clinical psychology: Aa modest proposal, Ameriean Psyetogist. Psychol, 10, 1974, 762.

19

. E.P. Sarafino, Applied behavior aBehavior Analysis, 2012, Wiley.

20

. M.R. Burch and J.S. Bailey, How dogs + Dogs Learn, 1999, Howell Book House.

21

. S.G. Friedman, A framework for solving behavior problems: functional assessment and intervention planning, Jurnal of Exotic PetMedicine161. Exot. Pet Med. 16, 2007, 6-10.

22

. K. Pryor, Lads before the wind: Adventures in porpoise $\neq$ Wind: Adventures in Porpoise Training, 1975, Harper Collins Publishers.

23

. K. Pryor, Don't shoot the dShoot the Dog, 1984, Bantam.

24

. K. Ramirez, Animal training: suecessful animal management through positive +Training: Successful Animal Management Through Positive Reinforcement, 1999, Shedd Aquarium; Chicago.

25

. K. Pryor and K. Ramirez, Modern Animal Fanimal training, The Wiley Blackwell Handbook of Operant and Classical Conditioning, 2014, 453-482.

26.

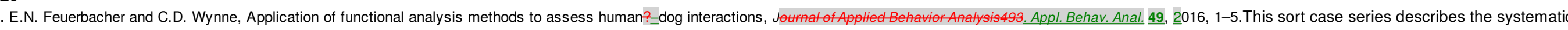

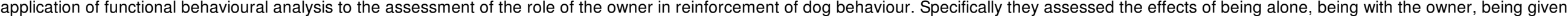
attention by the owner, the presence of a comfortable bed and toys on the behaviour of dogs. They found that simply access to the owner may serve as a reinforcer in a behavioural shaping paradigm.

27

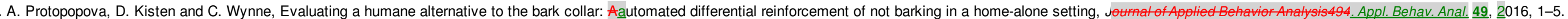

28

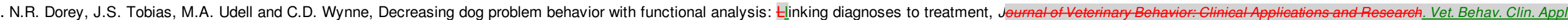
Res. 5, 2012, 276-282.

29

. K. Pryor, Reaching the animal mind: elicker training and ithat it teaches us about all aAnimal Mind: Clicker Training and What It Teaches Us about All Animals, 2009, Simon and Schuster.

30

J. Bailey and M. Burch, Ethics for behavior aBehavior Analysts, 2016, Routledge.

.P.C. Friman, S.C. Hayes and K.G. Wilson, Why behavior analysts should study emotion: Fthe example of anxiety, Jurnal of Applied Behavior Analysis317. Appl. Behav. Anal. 31, 1998, 137-156.

32

. L.U. Sneddon, R.W. Elwood, S.A. Adamo and M.C. Leach, Defining and assessing animal pain, Animal Behaviour3097. Behav. 30, $2014,201-212$.

33

. K.L. Overall, Clinical behavioral medieine for small aBehavioral Medicine for Small Animals, 1997, Mosby-Year Book, Inc.

34

P. Pageat, Pathologie du comportement du chien, 1995, Editions Dupont Vététrinaire; Maisons Alfort Cedex. 1995-Maisons-Alfort Cedex. 


\section{elsevier_COBEHA_361}

$\underline{3} 5$

. M. Loughlin, G. Lewith and T. Falkenberg, Science, practice and mythology: Aa definition and examination of the implications of scientism in medicine, Health Care Analysis212 21, 2013, 130-145.

36

. K.L. Overall, Assumptions versus science: Wwhy science always wins, Journal of Veterinary Behavior: Clinical Applications and Research72. Vet. Behav. Clin. Appl. Res. 7, 2012, 59-60.

37

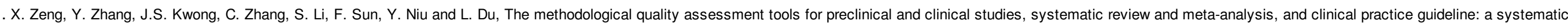
review, Jurnal of Evidence Based Medicine87. Evid. Based Med. $\underline{8}, \underline{2015}, 2-10$.

38

S. Every-Palmer and J. Howick, How evidence-based medicine is failing due to biased trials and selective publication, Jurnal ofevaluation in elinical practice206. Eval. Clin. Pract. 20, 2014, 908-914.

39

S. Vanheule, Diagnosis in the field of psychotherapy: Aa plea for an alternative to the DSM-5, Psychology and Psychotherapy: Theory, Research and Practice.852. Psychother. Theory Res. Pract. 85, 2012, 128-142.

40

. C. Newnes, The Diagnostic and Statistical Manual: Adiagnostic and statistical manual: a history of critiques of psychiatric classification systems, De-Medicalizing Misery II, 2014, Palgrave Macmillan; UK, 190-220.

41

D. Pilgrim, Historical resonances of the DSM-5 dispute American exceptionalism or Eurocentrism?, History of the Human Seienees27220149711742. Hum. Sci. 27, 2014, $\underline{97-117 .}$

$\underline{42}$

. American Psychiatric Association, -DSM 5.DSM 5, 2013, American Psychiatric Association.

2013-43

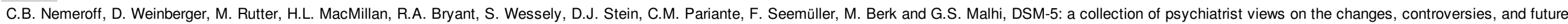
directions, $B M C$ dieine117Med. 11, 2013, 1.

44

. B.J. Carroll, Biomarkers in DSM-5: lost in translation, Australian and New Zealand Journal of Psyehiatry477. N. Z. J. Psychiatry 47, $2013,676$.

45

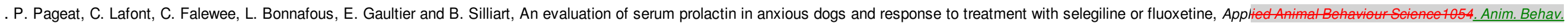
Sci. $105,2007,342-350$.

$46 . \cdot$

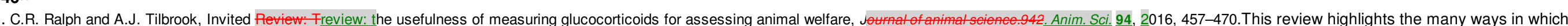

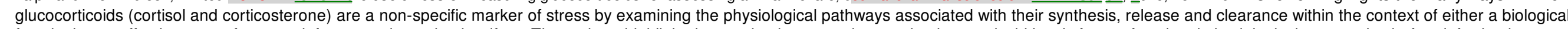

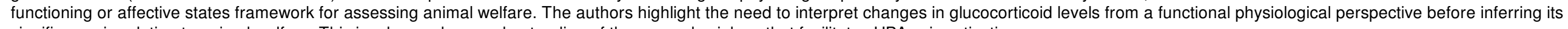
significance in relation to animal welfare. This involves a deep understanding of the neurophysiology that facilitates HPA axis activation.

47

. A.L. Podberscek, Y. Hsu and J.A. Serpell, Evaluation of clomipramine as an adjunct to behavioural therapy in the treatment of separation-related problems in dogs, The Veterinary record 14513 Vet. Rec. $145,1999,365$.

48

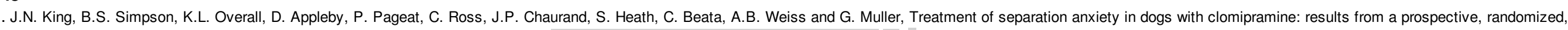
double-blind, placebo-controlled, parallel-group, multicenter clinical trial, Applied Animal Behaviour Science674. Anim. Behav. Sci. 67, 2000, 255-275.

49

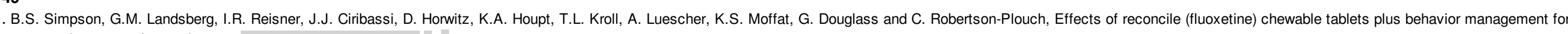
canine separation anxiety, Velerinary Thapeuties81. Ther. $\underline{8}, \underline{2007,} 18$.

50

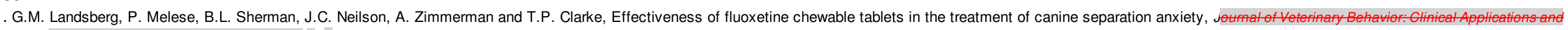
Pesearch37. Vet. Behav. Clin. Appl. Res. 3, 2008, 12-19.

51

. National Office of Animal Health, Compendium of Data Sheets for Animal Medicines, 2014, p 822.

52 


\section{elsevier_COBEHA_361}

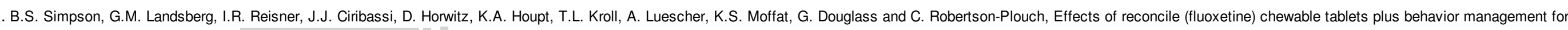
canine separation anxiety, Veterinary Therapouties 81 . Ther $\underline{8}, \underline{2007,18 .}$

53

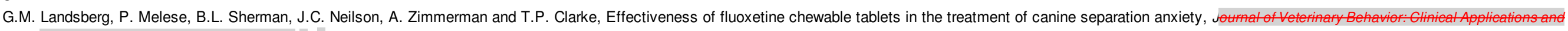
Research37. Vet. Behav. Clin. Appl. Res. 3 , 2008, 12-19.

54

.E. Blackwell, R.A. Casey and J.W. Bradshaw, Papers \& ArtielesThe Veterinany Recordarticles, Vet. Rec. 158, 2006, 551-554.

55

. C. Day and K.B. Higginbottom, Animal behavior case of the month, Journal of the American Veterinary Aledical/Association2428. Am. Vet. Med. Assoc. 242, 2013, 1071-1073.

56

. J. Panksepp, Affective neureseienee: The foundations of human and animal eNeuroscience: The Foundations of Human and Animal Emotions, 1998, Oxford university press.

57

. K.A. Lindquist, T.D. Wager, H. Kober, E. Bliss-Moreau and L.F. Barrett, The brain basis of emotion: a meta-analytic review, Behavioral and Brain Scienees3503. Brain Sci. 35 , $2012,121-143$.

58

. E.T. Rolls, What are emotional states, and why do we have them?, Emotion Review 53 . Rev. 5, 2013, 241-247.

59

. J. LeDoux, Rethinking the emotional brain, Neuron 73, 2012, 653-676.

60

. A. Damasio, Fundamental feelings, Nature 413, 2001, 781.

61

. A.R. Damasio, Emotions and Feelings: A Neurobiologieal Pfeelings: a neurobiological perspective, In: Feelings and Emotions: The Amsterdam Symposium, June, 20012004, Cambridge University Press, 49-57.

62

. S. Gallagher and D. Zahavi, The phenomenologieal mPhenomenological Mind, 2013, Routledge.

63

.K.S. Kendler and J. Parnas, Philosophical issues in plssues in Psychiatry: Explanation, phenomenology, and nPhenomenology, and Nosology, 2015, JHU Press.

64

. K.R. Scherer and P. Ekman, Approaches to eEmotion, 2014, Psychology Press.

65

. K.R. Scherer, Facets of emotion: Reeent rEmotion: Recent Research, 2013, Psychology Press.

66

. Reisner I:- An overview of aggression. BSAVA Manual of eanine and feline behavioural medieine. 2002 pp 181-Canine and Feline Behavioural Medicine. 2002 pp $181-194$.

67

. T. Dobzhansky, Nothing in biology makes sense except in the light of evolution, The Am Biol. Teach. 75, $2013,87-91$.

68

.D. Fraser, D.M. Weary, E.A. Pajor and B.N. Milligan, A scientific conception of animal welfare that reflects ethical concerns, Animat. Welfare 6, 1997, 187-205.

69

. D.S. Mills, Medical paradigms for the study of problem behaviour: a critical review, Applied Animal Behaviour Science813. Anim. Behav. Sci. 81, 2003, 265-277.

70

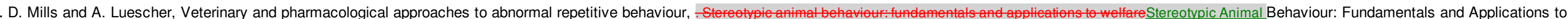
Welfare, 2006, 325-356.

71

. H. Zulch and D. Mills, Life skills for pSkills for Puppies, 2012, Veloce Publishing Ltd. 


\section{elsevier_COBEHA_361}

72

. K. Popper, The togie of seientifie dLogic of Scientific Discovery, 2005, Routledge.

73.

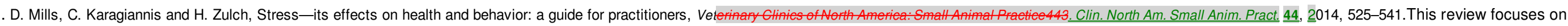

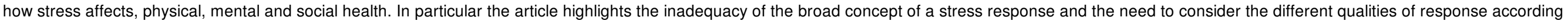

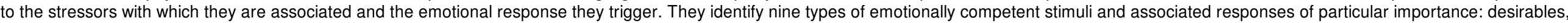

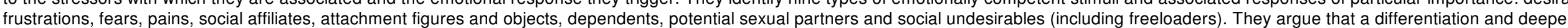

understanding of the physiological processes underpinning these reactions will lead to more specific predictions about the effects of specific classes of stressor on behaviour.

Highlights

- Three paradigms (Behaviofal, Medieal and Pysural, Medical and Psychobiological) are identifiable in clinical animal.

- Each approach has its own perspective on emotional expression and its importance.

- Evidence for animal emotion must be systematic and falsifiable to be scientificAssessing animal emotion in field seltings

\section{Queries and Answers}

Query: The author names have been tagged as given names and surnames (surnames are highlighted in teal color). Please confirm if they have been identified correctly. Answer: Yes

Query: As per journal stylesheet specification Abstract must consist of 120 words, kindly rephrase or provide new abstract of not more than 120 words.

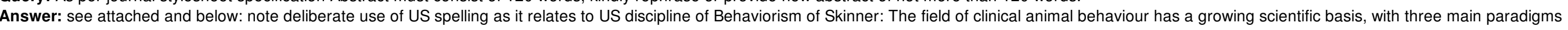

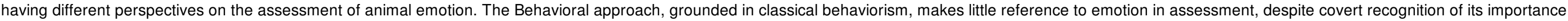

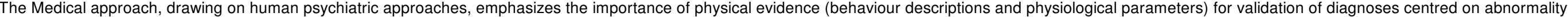

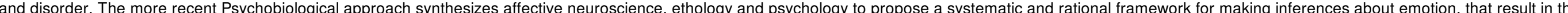
construction of testable (falsifiable) hypotheses relating to four domains derived from component process theory using field-based evidence.

Query: As per journal stylesheet specification "Conflict of interest statement" is mandatory. Please provide "Conflict of interest statement."

Answer: The author is one of the originators of the Psychobiological model, but has no competing financial interests or conflicts to declare

Query: Please provide publisher name for Ref. [70].

Answer: CABI Wallingfrod, Oxon 